\title{
Research on the settlement of levee and the formation mechanism of pavement crack in heightening and thickening levee engineering
}

\author{
Donghe $\mathrm{Ma}^{1,2^{*}}$, Chun Tan ${ }^{1,2}$, Xin $\mathrm{Liu}^{3}$, Peng $\mathrm{Wang}^{4}$, and Songling Han ${ }^{5}$ \\ ${ }^{1}$ China Water Northeastern Investigation, Design \& Research Co., Ltd., Changchun, Jilin, 130000, China \\ ${ }^{2}$ Research Center on Cold Region Engineering Ministry of Water Resources, Changchun, Jilin, 130000, China \\ ${ }^{3}$ State Grid Xinyuan Holding Co., Ltd, Beijing, 100761,China \\ ${ }^{4}$ Taonan City Flood Control and Drought Relief Service Center,Taonan,Jilin,137100,China \\ ${ }^{5}$ College of Construction Engineering, Jilin University. Changchun, Jilin, 130000, China
}

\begin{abstract}
In view of the heightening and thickening levee project which already built, the settlement and deformation on the top of the landside slope of levee and the cracks on the levee were investigated. The finite element method was used to simulated the settlement of the levee. The results show that after heightening and thickening, the thickness of the new filled soil is uneven in the cross-sectional direction of the levee, resulting in a significant difference in the distribution of additional stress and settlement. In addition, the top of the original levee has smaller deformation, while the newly filled levee has larger deformation, which causes uneven settlement on the top of the embankment. The presented results have guiding significance for the settlement and deformation prevention of levee project.
\end{abstract}

\section{Introduction}

Levee is an important hydraulic structure that plays the important role of flood discharge, sand discharge, and resistance to sea tides. The uneven deformation of the embankment soil will cause the cracking of the road surface, which seriously affects the use and maintenance of the embankment road. For the uneven settlement of the embankment soil, in addition to the necessary investigation and monitoring at the construction site, it is also necessary to predict in advance whether the embankment soil may undergo uneven settlement. In recent years, researchers have carried out a lot of research on the uneven settlement of the top of the embankment. With the deepening of the research on this problem, a series of prediction and calculation methods have been formed: numerical simulation, centrifugal model experiment, ant colony prediction algorithm and random medium theory [1-8]. The finite element analysis method can simulate the stress and strain field of the soil more accurately, and the results are intuitive and clear, it is an effective method to research the uneven settlement of the soil.

In the project of heightening and thickening levee, the soil of the original levee may have completed the primary consolidation and entered the secondary consolidation stage, and the new fill still needs to be consolidated. The inconsistency in the consolidation state and the consolidation stage of the two may cause uneven settlement of the top of the levee after the completion of the heightening and thickening levee, and then the cracking of the top of the embankment. Therefore, it is necessary to calculate the consolidation of the levee soil and estimate the remaining consolidation [9-12].

The research objectives of this paper are: 1 . Analysing the causes of uneven settlement of the road surface on the top of the embankment; 2 . constructing the numerical model of the levee and calculate its deformation; 3 . using the consolidation theory to calculate and predict the remaining settlement of the levee.

\section{Project Overview}

An existing levee project was heightened and thickened by adding clay on the landside slope. The flood control design standard is 50 -year frequency, and the dike level is level 2. The cross-sectional dimension of the levee: the width of the top of the levee is $8.0 \mathrm{~m}$, the slope ratio of the riverside slope and the landside slope is 1:3.0. The riverside slope was protected by the Reynolds mat, and the sod revetment was adopted on the landside slope. The thickness of the Reynolds mat is $0.23 \mathrm{~m}$, with a $0.10 \mathrm{~m}$ thick sand gravel cushion and a layer of non-woven fabric or geomembrane. The road with concrete pavement was built on the top of the embankment, which was designed according to the fourth-grade highway: the design speed is $20 \mathrm{~km} / \mathrm{h}$, the thickness of the concrete pavement is $20 \mathrm{~cm}$, and the concrete bending strength is more than 4.5MPa.

*123madonghe@163.com 


\section{The observation, cause analysis on settlement of levee and pavement crack.}

\subsection{Settlement and pavement cracks}

A detailed investigation was conducted on the levee. It was found that the obvious settlement was occurred in the landside slope of heightened and thickened section. And the cracks were appeared at the corresponding locations. Formed a banded shaped settlement concentration area of $3 \mathrm{~m} \times 22 \mathrm{~m}$, and the maximum height difference between the riverside slope and the landside slope is $12 \mathrm{~cm}$.

\subsection{Analysis of causes of cracks}

According to the results of the survey on the appearance quality of the pavement, it was found that the study case was mainly appeared uneven settlement coupled with the cracks occurred on the concrete pavement. The causes of pavement failure were analysed according to the combination of the measurement of levee section and the drawing documents:

(1). The new filled soil of landside slope is thicker than that of riverside slope, which was shown in the section drawing (Fig 1.). That leads to the self-weight stress of the soil to settlement on the landside slope is more than that of the riverside slope. When coupled with the loads on the levee's top, the settlement of the landside slope is more than that of the riverside slope. That is to say the uneven Y-deformation caused by the inhomogeneity of self-weight stress may lead to cracks on the pavement.

At the same time, the deformation modulus of new filled soil may different from that of the original soil. The ability to deform of the landside slope and riverside slope may be different.

In summary, the inhomogeneity of the thickness of the newly filled soil may lead to the difference of loading and the ability to deform, which may cause the uneven deformation on the pavement.

(2). The effect of construction period

There is almost one year between the completion of the levee fill and the beginning of the pavement construction. The primary consolidation was insufficient both of the new filled soil and the soil of dike foundation, which lead to the obvious vertical settlement on the pavement when construction complete. The strongest destruction phenomenon (uneven settlement, inclined and cracking of pavement) is appeared on the heightening and thickening section of original levee, which is due to: 1 , the differences of settlement on new filled soil and dick foundation; 2, the inhomogeneity of the thickness of the newly filled soil.

And differential settlement may develop with gradual consolidation, which further intensifies the cracking of the pavement.

\section{The numerical simulation of the levee}

The finite element method was used to simulated the deformation of the levee. The numerical model was built based on the section drawing. In order to eliminate the influence of the boundary effect, the model extends the width of the dam along the left and right directions, and the model extends the thickness of the dam downward. Normal constraints are imposed on the left and right boundaries and the bottom boundary of the model. The mechanic parameters of material were obtained from the results of site experiment and lab experiment (Table 1).

Table 1 Mechanic parameters

\begin{tabular}{ccccc}
\hline Numbering & Soil & $\begin{array}{c}\text { Elastic } \\
\text { modulus: } \mathrm{E} \\
(\mathrm{Mpa})\end{array}$ & $\begin{array}{c}\text { Density: } \gamma \\
\left(\mathrm{g} / \mathrm{cm}^{3}\right)\end{array}$ & $\begin{array}{c}\text { Poission } \\
\text { ratio: } \mu\end{array}$ \\
\hline 1 & Clay & 4.6 & 1.63 & 0.35 \\
2 & $\begin{array}{c}\text { Sandy soil } \\
\text { (Poorly } \\
\text { graded) }\end{array}$ & 20.0 & 1.75 & 0.27 \\
3 & $\begin{array}{c}\text { Low liquid- } \\
\text { limit clay }\end{array}$ & 4.3 & 1.62 & 0.38 \\
\hline
\end{tabular}

Perform an initial static analysis of the dike. LinearElastic linear elastic model was used to study the initial stress state of the dam and dam foundation soil. The yield criterion is the Ducan-Chang yield criterion. Assuming that the soil has no initial displacement, the ground stress of the levee has been released, and there is no influence of tectonic stress. Therefore, the self-weight stress field was used as the initial stress condition. The initial stress in the vertical direction can be calculated according to the thickness of the overlying soil and distributed linearly along the depth. The stress in the horizontal direction is calculated by the lateral pressure coefficient. The materials and boundary conditions of the model are shown in Fig 2

The calculation results of finite element method show that the maximum settlement of the top of the levee in the calculated section is $6.5 \mathrm{~cm}$, which is located at the top of the heightened and thickened area (Fig 3). The vertical settlement value on the top of original levee is $3.5 \mathrm{~cm}$. Since the settlement of the original levee is basically stable, after the heightening and thickening is completed, the thickness of the new fill is uneven in the direction of the cross section of the dike, the additional stress generated by it and the settlement of the new fill itself are significantly different in each part, showing an old The top of the embankment has a small deformation and the newly filled embankment has a large deformation, causing uneven settlement on the top of the embankment. At the same time, this also verifies the difference in settlement caused by the difference in the deformation capacity of the landside slope and riverside slope which is proposed in Section 2.2.

In the $\mathrm{X}$ direction, the new filled soil deforms to the right as a whole, and the maximum displacement in the $\mathrm{X}$ direction is $1.2 \mathrm{~cm}$. The original soil deformed to the left, and the maximum displacement was $1.2 \mathrm{~cm}$. At the same time, the entire pavement at the top of the levee has a 
displacement to the right in the $\mathrm{X}$ direction, with a maximum of $0.8 \mathrm{~cm}$. This shows that the cracks caused by the separation of the original and new filled of the embankment are distributed inside the levee body and may not have affected the road surface on the top of the levee.

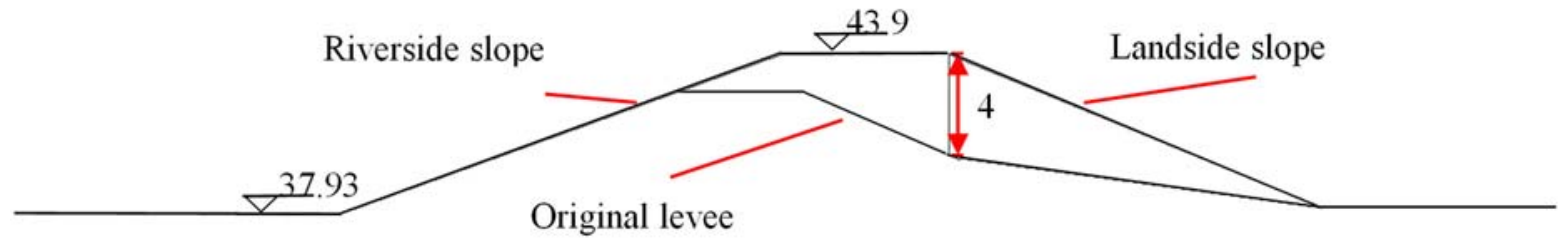

Fig 1. The section drawing of the levee. (Unit: m)

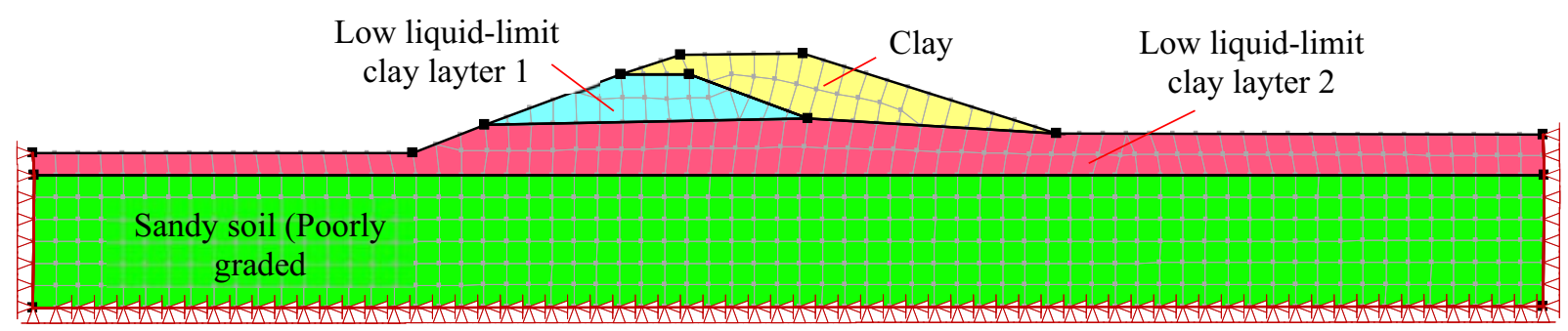

Fig 2. The numerical model of the levee. (Unit: m)

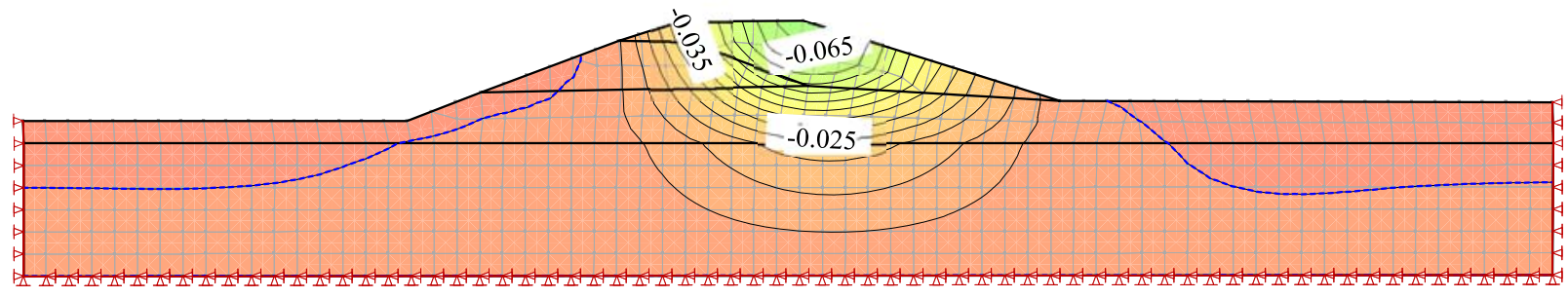

Fig 3. The countor map of Y-displacement. (Unit: m)

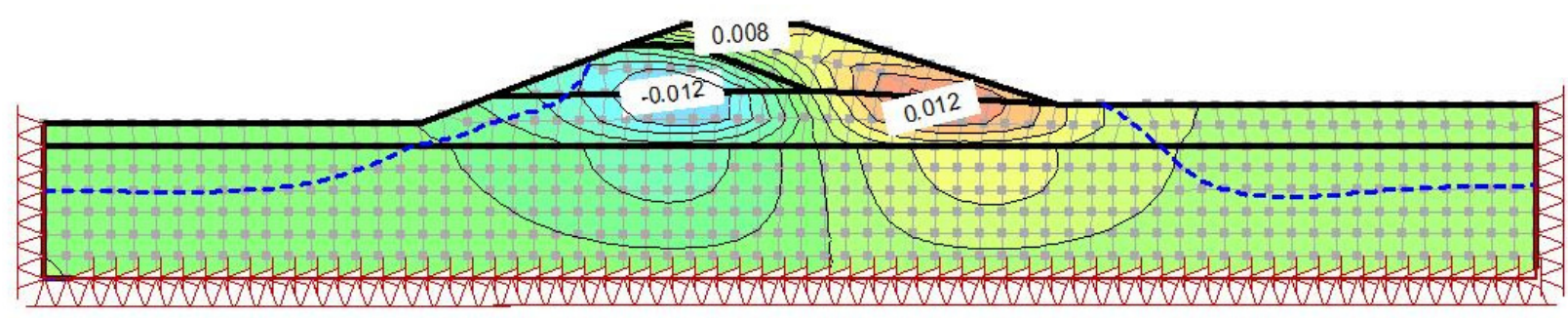

Fig 4. The countor map of X-displacement. (Unit: m)

\section{Calculation and analysis of residual settlement on levee}

An indoor consolidation test was carried out with soil samples taken from the site to research the settlement in the study area. It is assumed that the primary consolidation accounts for $80 \%$ of the total consolidation, and the remaining $20 \%$ is the secondary consolidation. The time required for the sample to reach $80 \%$ of the total consolidation is shown in Table 2. According to the formula of consolidation theory:

$$
\frac{t_{1}}{H_{1}^{2}}=\frac{t_{2}}{H_{2}^{2}}
$$


Among them, $\mathrm{H}_{1}$ is the thickness of soil layer $1 ; \mathrm{H}_{2}$ is the thickness of soil layer $2 ; t_{1}$ is the time required for soil layer 1 to complete all consolidation; $t_{2}$ is the time required for soil layer 2 to complete all consolidation.

And the results of prediction of residual settlement of the section is shown in Table 2.

\begin{tabular}{|c|c|c|c|c|c|}
\hline $\begin{array}{l}\text { Time of } \\
\text { sample } \\
\text { consolida } \\
\text { tion } t_{1}(h)\end{array}$ & $\begin{array}{c}\text { High } \\
\text { t of } \\
\text { the } \\
\text { sam } \\
\text { ple } \\
\mathrm{h}_{1} \\
(\mathrm{~m})\end{array}$ & $\begin{array}{l}\text { Thickn } \\
\text { ess of } \\
\text { the fill } \\
h_{2}(m)\end{array}$ & $\begin{array}{c}\text { Time of } \\
\text { fill } \\
\text { consolida } \\
\text { tion } \mathrm{t}_{2}(\mathrm{~h})\end{array}$ & $\begin{array}{c}\text { Time of } \\
\text { new fill } \\
\text { consolida } \\
\text { tion (h) }\end{array}$ & $\begin{array}{c}\text { Residual } \\
\text { deforma } \\
\text { tion of } \\
\text { levee } \\
(\mathrm{cm})\end{array}$ \\
\hline 1.67 & 0.02 & 3.95 & 27196 & 53232 & 1.3 \\
\hline
\end{tabular}

\section{Discussion}

This article combines an actual engineering case to study the cracking phenomenon of the road surface on the top of the embankment caused by the uneven settlement of the embankment. Firstly, based on field survey data and engineering construction drawings, the causes of pavement cracking were studied, and some conjectures are put forward. Then, the finite element method is used to simulate the case in this paper, and the deformation cloud picture of the embankment after the increase in height and thickness is obtained, which supports the previous conjecture. Finally, the settlement of the top of the embankment was calculated, and the settlement of the top of the embankment was predicted. Numerical calculation results show that the mechanism of uneven settlement of the top of the embankment researched in this paper is correct and can provide a meaningful reference for related projects.

At the same time, the research in this article still has some limitations:

(1) Since the elastic modulus of soil is difficult to obtain through experimental methods, the difference in elastic modulus of new and old fill materials is not considered.

(2) The seepage phenomenon is not considered, simplifying the simulation conditions.

(3) The thickness changes of the original soil and the new fill were not considered when calculating the soil consolidation, and only the maximum settlement was calculated.

\section{Conclusion}

This paper researched the formation mechanism of pavement cracks on the top of the levee, calculates the settlement of the top of the embankment through numerical simulation, and uses the consolidation theory to calculate the remaining settlement in this case.

(1) The newly filled soil on the landside slope is thicker than that on the riverside slope. Therefore, under the uneven load, the settlement of the newly filled soil on the landside slope is greater than the settlement deformation of the newly filled soil on the riverside slope, resulting in uneven settlement and pavement cracks. At the same time, the difference in the deformation capacity of the soil on both sides in the vertical direction is also one of the reasons for the uneven settlement of the top of the embankment.

(2) The maximum settlement of the research section is $6.5 \mathrm{~cm}$, which is located at the top of the heightening and thickening area. The vertical settlement on the top of original levee is $3.5 \mathrm{~cm}$. Because the settlement of the original levee is almost reach stable status. After the heightening and thickening of the levee, the distribution of the new fill is uneven in the direction of the cross section, the additional stress generated by it and the settlement of itself are significantly different in each part of the levee. The top of the original levee has a small deformation while the newly filled has a large deformation, causing uneven settlement on the top of the levee.

(3) For dike heightening and thickening projects, cracks on the top of the dike are mainly caused by uneven settlement of the top of the dike. In the design and construction of the road on the top of the dike, sufficient attention should be paid to this problem. According to the calculation of the consolidation of the embankment soil, the maximum remaining settlement on the top of the embankment is $1.3 \mathrm{~cm}$.

In future research, the uneven settlement of the top of the embankment should be further studied from the perspectives of seepage of the embankment, stress path of the fill during construction, and consolidation of the fill.

\section{References}

1. T. Lan, J. Wang, APPL SCI-BASEL. $8: 2392(2018)$.

2. S.W. Jin, Y.W. Choo, Y.M. D.S. Kim, Kim, KSCE J CIV ENG.18 : 1036-1046 (2014)

3. F. Lopez-Caballero, C. Khalil, ASCE-ASME J RISK U A. 4 : 04018010 (2018).

4. R. Sukkarak, P. Jongpradist, P. Pramthawee, COMPUT GEOTECH. 108 : 244-256 (2019).

5. F.G. Sigtryggsdottir, J.T. Snæbjo“rnsson, L. J Grande, GEOTECH GEOENVIRON. 144 : 04018059 (2018).

6. M.E.Kartal, M. Çavusli, M. Genis, INT J GEOMECH. 19 (2019)

7. K. Chugh. Ashok, W. Davidson. Luther, CAN GEOTECH J. 25 : 716-725 (1988).

8. W. Zhou, J. J. Hua, X. L. Chang, C. B. Zhou, COMPUT GEOTECH. 38 : 269-280 (2011).

9. R. Sukkarak, P. Jongpradist, P. Pramthawee, COMPUT GEOTECH. 108 : 244-256 (2019).

10. F. X. Liu, G. H. Lei, CAN GEOTECH J. 57 : 466 (2020).

11. C. Y. Olgun, j. Guney. GEOTECH GEOENVIRON. 142 : 015015(1-4) (2016).

12. J. H. Yin, W. Q. Feng, CAN GEOTECH J. 54 : $333-$ 347 (2016). 